\title{
A Case Study of a Chinese learner's Learning Style in English Studying
}

\author{
Mi Zhang \\ (Rongzhi College of Chongqing Technology and Business University, 401320, China)
}

\begin{abstract}
This essay focus on the second language learning styles of a L2 learner, utilizing Learning style survey, designed by Andrew D. Cohen, Rebecca L.Oxford and Julie C.Chi, and self-designed interview. The data have indicated that the learner's learning style remained relatively constant throughout his time in language studying, but it would change in different environment, in different stages of learning English. And his learning style is related to his reading.

This essay is organized as follows. Section 2 gives a brief overview of learning styles. In section 3, it proposes research questions that would be investigated in this report. And section 4 and 5 provide methodology and information of participant. Section 6 presents the data and results. And section 7 considers these results with previous findings. Section 8 concludes this report.
\end{abstract}

Keywords: learning style; L2 learner; learning style preferences

DOI: $10.36012 /$ fhe.v2i1.1571

\section{Literature Review}

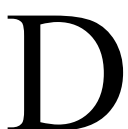

efinition learning styles are internally based characteristics of individual for the intake or understanding of new information ${ }^{[1]}$ (Reid, 1995). The term learning style represents the general approaches preferred by the students when they study. Students themselves get used to applying their own learning styles in comfort zone. In L2 learning, comfort zone would be learning situations that fits students' learning preferences. So learning style here refers to "an individual's natural, habitual, and preferred ways of absorbing, processing, and retaining new information and skills."(Reid,1995) and Keefe defines "learning styles are characteristic cognitive, affective, and physiological behaviours that serve as relatively stable indicators of how learners perceive, interact with, and respond to the learning environment... Learning style is a consist way of functioning, that reflects the underlying causes of learning behaviour." [2] (1979).

Learning style is an overall pattern that provides learners different methods to grasp knowledge. And the same learning style can be loved or hated by different people. Kolb thinks that learning can be classified into four parts, concrete experience, reflective observation, abstract conceptualization and active experimentation. Students would have partiality for these four processes. Therefore, it leads to four types of learning style preference: diverging which combines preferences for experiencing and reflecting, assimilating which combines preferences for reflecting and thinking, converging which combines preference for thinking and doing and accommodating which combines preference for doing and experiencing. ${ }^{[3]}(2005)$

And Reiff ${ }^{[4]}(1992)$ thinks that learning styles can be divided into five categories: environmental elements (sound, light, temperature, design), emotional elements (motivation, persistence, responsibility), sociological elements ( self, partner, mentor), and psychological elements (global-analytical, impulsive-reflective). Some are stable that can not change while some can be trained and change in different environment.

What's more, Rebecca L. Oxford proposes that "Within the area of learning style, each individual re flects sensory style dimensions (visual/auditory/hands- 
on) and social style dimensions (extroverted/introverted)." and it also has cognitive style dimensions, which are concrete-sequential/abstract-intuitive, closure-oriented/open, detail-focused/holistic (sometimes called particular/global), and analyzing/synthesizing. ${ }^{[5]}(2003)$

Different learner types are believed to exist. And since the late $20^{\text {th }}$ century, researchers and educators have designed some instruments to assess learning styles. ${ }^{\text {ต }}$ (Dunn,1984). Ehrman \& Leaver have established a "learner profile schema usable for diagnosis and advising language learners with ten cognitive style dimensions. Most of them well-known (e.g. field independence, leveling-sharpening, random-sequential)." and during their research, they find many crucial conclusions, like Field independence as learning style, prefers to separate what is considered important from text, while field dependence would focus on the whole context. Random learners would like to work out their own learning sequences while sequential learners would learn step-by-step. ${ }^{[7]}$ (Ehrman \& Leaver,2003) and there are some other conclusions about the different learning styles.

And in Reid's research, she thinks that people learn through their sensory and everyone has their own preferences. Reid also points that "General speaking, the results of this study showed that ESL students strongly preferred kinesthetic and tactile learning styles." and "Graduate students indicated a significantly greater preference for visual and tactile learning than undergraduates." ${ }^{[8]}(1987)$ and Carbo(1983) thinks that good learners prefer to learn through their visual and auditory senses while poor readers have a stronger preference for tactile and kinesthetic learning.

And there are still many instruments designed to assess learning styles. Although many instruments are different, they share the same goal of identifying the nature of individual difference in learning.

\section{Research Questions}

This study aims at investigating the language learning style preferences of a Chinese EFL learner and tries to figure out if his learning styles would be different during his different stage, time and process of learning, if his learning style is related to reading.

\section{Methodology}

The study reported here uses Julie C. Chi, Rebecca Oxford, Andrew Co hen's Learning Style Survey which assess learners' general approach to learning. This survey does not predict learners' behavior in every instance, but gives a clear indication of students' own learning preference. And this survey gives specific descriptions about each learning preference which helps learners to take advantages of ways they learn best. The way to research is to give participant about 30 minutes to complete the survey, and then total the points in each part, write the results in the blanks and circle the higher number in each part. If points are close, both aspects of styles should be circled. At the Note part, it gives directions and explanations about every style preference. Using these explanations helps to understand and investigate participant's learning styles.

In addition, participant would also take an interview which draws on participant's conscious knowledge and perceptions of learning styles. The author gathered information from several open-ended, learning-related interviews with participant. And then author tries to link information from interview with results from Learning Style Survey. And by comparing with the previous findings, author gets general conclusion.

\section{Participant}

The participant in this study is a 25 -year-old man from China. F (pseudonym) began to study English in junior school. And in the later few years in the high school and university, he continued to learn English in daily classes. And after he graduated in 2012, he had worked for an advertising agency for about 3 years. He had never gone abroad to work, study or live. Everyday he getting in touch with is a pure Chinese-language environment. After he resigned, he took some English classes again to prepare IELTS test (International English Language Testing Systems). And now he is a postgraduate in the University of Essex.

\section{Data analysis and results}

Here the Learning Style Survey provides evidences about F's learning styles. In the first part How I use my physical senses. It has thirty statements, and every ten statements refer to an aspect of sensory learning styles. First is visual, second is auditory and the third is tactile/kinesthetic. And F gets 27, 23, 26 in order. According to the scores he gets, his sensory style preferences are visual and tactile/kinesthetic. And in the in- 
terview, when I asked him about "Do you think which way is easy to understand new knowledge, through you eyes? Ears? Or hands?" He replied me that he likes learning by seeing which makes impression on him.

In the part 2 How I expose myself to learning situations, it provides twelve statements about different situations. The score in the first half which refers to extraverted style is 16 , while the score in another part which refers to introverted style is 14 . It means that $\mathrm{F}$ would expose himself to learning situations in an extraverted way. At the same time, he said he is an outgoing person. When he feels stressed, he would "Eat chocolate, walk around, go to the party" and "would not stay at home alone".

In the part 3 How I handle possibilities, it also has two parts $\mathrm{A}$ and $\mathrm{B}$, and $\mathrm{F}$ gets 20 in $\mathrm{A}$ and 13 in $\mathrm{B}$. Here $\mathrm{A}$ represents random-intuitive and $\mathrm{B}$ represents concrete-sequential. What's more, when I asked him about "How do you learn? On your own sequences or follow the guide from teachers and learn step-by-step?" His answer is that he has his own plan and would follow his own step.

In the part 4 How I deal with ambiguity and with deadlines, it has eight statements about this part. And the first four refers to closure-oriented learning and the last four refers to open learning style. And F gets 12 in the first part and 8 in another. So the result shows that he is closure-oriented. In the interview he expressed that most time before he would study, he prefers to make a plan, about how to start, when to do tasks and when to finish it.

In the part 5 How I receive information, this part refers to global and particular learning styles. And $\mathrm{F}$ gets the same scores 12 in part A and B. It seems that he is neutral in the survey here. But later in the interview, he acted to be more global. I asked him about how he would do when reading. Would he focus on the whole context or on the details? He said that most of time he would pay much attention to the general ideas. Even sometimes there are some words or sentences he could not understand, he would not care about these. He would skip it or use contextual clues to the meaning. And I also gave him a question about what will he see first about the forest and trees. And the answer is he would see fore st at first. And this question also relates to Part 9 about How I deal with multiple inputs. He also gets the same scores 9 and 9 in these two parts. But according to his answer about seeing forest first and focusing on the whole context, it shows that he is filed-dependent.

In the part 6 How I further process information, it also has ten statements which are divided into two parts: synthesizing and analytic. The score F gets in the part $\mathrm{A}$ is twice as much as that of part B. Besides, he told me that when he reads articles in daily life or works, he prefers to use pieces to build new models and tries to get new idea or information from this article. He enjoys guessing the meaning of unknown words. There is no particular reason that forces him to act like this way, it is just his habit. He gets used to doing in this way. The result in Learning Style Survey is corresponding to the conclusion from the interview: $F$ tends to be synthesizing.

In the part 7 How I commit material to memory, he gets the same scores in these two sections once again. But according to the interview, his answers about "when you learn new materials, will you connect these with previous knowledge or make distinctions?" and "What would you be more focused, the accuracy of knowledge or the expediency of knowledge?" reveal that he is a leveler. And the following is his answers: "In most cases, I am willing to use my previous knowledge to understand the new input. I think it can help me to understand better and I can remember new knowledge very well. If you give me a choose about the accuracy and expediency of the knowledge, I would choose the later one which can broaden my horizon."

In the part 8 How I deal with language rules, it contains two aspects: inductive and deductive. And F gets 8 in inductive and 6 in deductive. This result conforms to the interview. He said he prefers the teaching way that teachers can give a lot of examples and he can find rules by himself, rather than the way that teachers give rules in advance and he applies these rules into practice.

In the part 10 How I deal with response time, $\mathrm{F}$ gets 10 in impulsive part and 8 in reflective part. It shows that he is impulsive. And during the whole interview, he reacted very quickly and didn't spend too much time thinking. And these two results all say he is an impulsive person.

And in the last part 11 How literally I take reality, 
F gets 5 in metaphoric part and 7 in literal part. In the interview, I asked him "when learning English, what do you prefer? Learning materials that are given or Learning and trying to understand the whole grammar system or other information involved?" and he replies quickly: "of course I like to learn material that are given which can not only save my time, but become easier for me to grasp new knowledge."

And in the later interview, I asked him whether his learning habits changes in his different stages of learning English. He indicated that only some of his learning habits change as he gets older. Like in the past, he often finished his homework alone but now he likes to study in groups which give him space to discuss and analysis some questions. And when he was young, he may felt shy to answer teacher's questions. But now, he is confident in raising questions and doing presentations in class. The reason why his learning styles change is that he is exposed to different learning environments and he has more experience: working and studying. It forces him to change some habits.

\section{Discussion}

To sum up, as indicated by Learning Style Survey, F's learning style is visual, tactile/kinesthetic, extraverted, random-intuitive, closure-oriented, global, synthesizing, inductive, field-dependent, impulsive and literal. $\mathrm{He}$ is also a leveler. Some of his learning style changes during his different stages. He also has his own plan, own methods, and own reading preferences in English studying. And the interview supports the results of the survey.

According to the literature, Keefe thinks that "learning styles serve as relatively stable indicators of how learners perceive, interact with, and respond to the learning environment." ${ }^{[9]}(1979)$ Learners' learning style is habitual that seldom changes during one's life. But we can not ignore the influence of the environment. Keefe also says that "Learning style is a consist way of functioning, that reflects the underlying causes of learning behaviour." (1979) it means that learning style reflects learning behavior. So under some reasons caused by environment or one's own experience, learning style can slightly change. And according to the self-assessment of F, he does think some of his behaviors change. And Cheng and Banya hold the view that "some (learning styles) are biological and stable, such as individual's response to sound, light, and tem- perature. Others are developmental and flexible, such as perceptual preferences, motivation and reflectivity; that is, they can be trained and extended." What's more, Joy Reid points that "Learning styles are a result of both nature and nurture." ${ }^{[10]}(1998)$ Samuel Messick also reports that different individuals perform the same task in different ways, and that the same individual might perform in a different manner across items or on different occasions. ${ }^{[1]}$ (1976) Therefore, F's learning style is changeable through his different time of learning English. This conclusion is corresponded to previous findings.

And in the Marian Tyacke's research, there are two kind of students, one is "more inclined to use their reasoning and analytical skills, make conscious choices, compare and select, then retain or discard information." another "read more quickly and extensively, but may be inaccurate answering questions about details. "and the result is that the former group may appear to be more successful in traditional assessment situations. ${ }^{[12]}$ (1998) Turning to the interview which relates to the reading, it embodies the same finding. F got 6.5 in the IELTS test reading part which can not be regarded to have a high level of competence of English. F said that during taking reading test in IELTS, he read quickly in order to finish all the questions in a limited time. In reading part, it has various types: short answer questions, sentence completion, multiple choice, matching headings to sections, gap fill and so on. Most of these requires accurate details not general ideas. So F can understand what each articles talk about, but still lost some points. At the same time, according to the survey, $\mathrm{F}$ is global, synthesizing, and field-dependent that will pay much attention to the whole context and ignore some specific details. ${ }^{[13]}$ (Ehrman \& Leaver,2003) it might be argued that learning style here he obtains can not be regarded as factor which could influence reading scores. Because the proficiency, the status of taking exams can also influence the results. Crucially, however, learning style here is not thought to be the only factor that relates to reading. It is habitual behavior that could happen unconsciously during his studying, his reading.

\section{Conclusion}

In this report, by combining Language Learning Survey and self-designed interview, we can know participant F's learning style. And his learning style changes 
with the time and environment. At the same time, his learning style, such as global, field-dependent, and synthesizing style, influences his reading in daily study or in the test.

Importantly, however, the survey here can not present the accurate learning style F has, it is the general assessment. And the factors that will influence reading achievement are variable, such as learning strategies, learning belief, learning aptitude and so on. In the further study, we should try to connect these factors to investigate what is also related to English reading for L2 learners, and what degree do these factors function.

\section{References}

[1] Reid, J. (Ed). 199 5. Learning styles in the ESL/EFL Classroom. Boston, MA: Heinle and Heinle Publishers.

[2] Keefe, J. W. 1979. "Learning Style: an overview." In Student Learning Styles.

[3] Kolb, Alice Y. \& David A. Kolb. 2005. The Kolb Learning Style Inventory-Version 3.12005 Technical Specifications, Experience Based Learning Systems, Inc, Case Western Reserve University.

[4] Reiff, J. 1992. What research says to the teacher: Learning styles. Washington, DC: National Education Association.

[5] Oxford, Rebecca. Language Learning Styles and Strategies: Concepts and relationships. Walter de Gruyter. Univetsity of Edinburgh. 2003

[6] Duun, R.1984. Learning styles: State of the science theory into practice, 23,1, pp.11-19.

[7] Ehrman, Madeline \& Leaver, Betty Lou. 2003. Cognitive styles in the service of language learning. Washington DC: Elsevier Ltd.

[8] Reid, Joy M. 1987. The Learning Style Preferences of ESL Students TESOL QUARTERLY, vol, 21, no.1.Colorado State University.

[9] Keefe, J. W. 1979. "Learning Style: an overview." In Student Learning Styles.

[10] Cheng, Maria Hsueh-Yu. \& Banya, Kingsley. 1998. 'Bridging the Gap Between Teaching Style and Learning Styles' in Joy M. Reid. (Ed.) Understanding Learning Styles in the second language classroom. University of Wyoming.

[11] Messick, S. 1976. Personality consistences in cognition and creativity. In S. Messick, Ed., Individual in Learning: Implications of Cognitive Styles and Creativity for Human Development(pp.4-37). San Francisco: Jossey-Bass.

[12] Tyacke, Marian. (1998) 'learning Style Diversity and the Reading Class: Curriculum Design and Assessment' in Joy M. Reid. (Ed.) Understanding Learning Styles in the second language classroom. University of Wyoming.

[13] Ehrman, Madeline \& Leaver, Betty Lou. 2003. Cognitive styles in the service of language learning. Washington DC: Elsevier Ltd. 